\title{
The Effects of Rising Water Temperatures on Poecilia reticulata Native to Guyana
}

\author{
*Jonathan D. Jaipaul', Devya Hemraj² and Samantha Providence-Forrester ${ }^{3}$ \\ ${ }^{1}$ Department of Environmental Studies. Faculty of Earth and Environmental Studies. Turkeyen Campus. Greater \\ Georgetown, Guyana. *jaipauljonathan@gmail.com. \\ ${ }^{2}$ Centre for the Study of Biological Diversity and Department of Biology. University of Guyana. Turkeyen Campus. \\ Greater Georgetown, Guyana. \\ ${ }^{3}$ Faculty of Agriculture and Forestry. Turkeyen Campus. Greater Georgetown, Guyana.
}

DOI: $10.52377 / D P R L 8943$

The coastal region of Guyana is predicted to experience an increase in annual temperature. Climate change trends indicate that the mean minimum and maximum temperatures will rise above the climatological average. This change in mean temperatures will alter the favourable conditions within coastal ecosystems, which can affect biodiversity. One such at-risk organism is the Guppy (Poecilia reticulata), a species that is particularly sensitive to temperature variations within their habitats. This species was used to observe the potential effects of increasing temperatures on a native species within Guyana's context. This study sought to examine the effects of elevated temperatures on the reproduction and development of Poecilia reticulata by examining the parameters of brood size, sex ratio, and growth performance at sexual maturity. Treatments of $31^{\circ} \mathrm{C}, 32^{\circ} \mathrm{C}$, and a control treatment at room temperature $\left(27^{\circ} \mathrm{C}\right)$, were used to rear adult male and female Poecilia reticulata and subsequent fry after succeeding parturition. The results indicated that brood sizes increased with lower temperatures. Those reared at room temperature produced higher than those reared at $31^{\circ} \mathrm{C}$, while specimens reared at the highest temperature $\left(32^{\circ} \mathrm{C}\right)$ produced no progeny. Mortality was particularly observed for both male and female adult specimens at $32^{\circ} \mathrm{C}$, with females exhibiting morphological aberrations. The sex ratios of progenies differed from a balanced sex ratio (1:1): more females were observed in the control treatment, while more males were observed at $31^{\circ} \mathrm{C}$. However, neither sex ratio nor growth performance (length and weight gain) at $31^{\circ} \mathrm{C}$ was statistically significant ( $\left.p>0.05\right)$. Overall, these findings suggest that elevated temperatures can be harmful to Poecilia reticulata reproduction and development. Rising water temperatures may threaten the stability of the Poecilia reticulata population if climate change trends continue as predicted.

Keywords: Climate change; temperature; Poecilia reticulata 